\title{
PSEUDOPRECOCITY IN AN INFANT DUE TO A LUTEOMA OF THE OVARY
}

\author{
BY \\ P. E. CAMPBELL and D. M. DANKS \\ From the Departments of Pathology and Clinical Research, Royal Children's Hospital, \\ Melbourne, Australia
}

(RECEIVED FOR PUBLICATION DECEMBER 19, 1962)

Ovarian tumours are rare in children and account for approximately $1 \%$ of all the tumours of childhood (Schultz, 1926). The majority are benign, the commonest being cystic teratoma. Tumours causing sexual precocity and pseudoprecocity are particularly rare; Wilkins (1957), in a long experience of paediatric endocrinology, personally encountered only one case. The ovarian tumour most often responsible for sexual precocity and pseudoprecocity is the granulosa cell tumour. In a recent paper, Eberlein, Bongiovanni, Jones and Yakovac (1960) report two further examples of this tumour and review the world literature; they could find reports of approximately 60 definite cases, and 30 probable cases, of granulosa cell tumours causing sexual precocity. There are very few reports of thecomas and luteomas producing this syndrome.

The purpose of this short communication is to place on record a case of pseudoprecocious puberty due to a luteoma of the ovary.

\section{Case Report}

J.L. presented at the Royal Children's Hospital in July 1962 at the age of 10 months, because of vaginal bleeding. Three weeks before presentation she had bled for one day, and a week later bleeding recurred and continued. The mother estimated the total blood loss to be about that of a normal adult woman's menstrual volume. She had not noted any other abnormality and stated that this baby was no bigger than her siblings had been at the same age.

The pregnancy had been the mother's sixth and had been uneventful, with a normal spontaneous delivery at full term. The baby weighed 7 lb. $12 \mathrm{oz}$. $(3,515 \mathrm{~g}$.) at birth and breathed promptly. The second of the mother's pregnancies ended in a miscarriage, but there are four healthy siblings - three boys (born 1946, 1952 and 1958; birth weights $8 \mathrm{lb} .15 \mathrm{oz}$. (4,054 g.), $8 \mathrm{lb} .9 \mathrm{oz}$. $(3,883$ g.), 8 lb. 9 oz. (3,883 g.) and a girl (born 1949 , birth weight 7 lb. 12 oz. (3,515 g.)). This 13-year-old sister is not yet menstruating but has some breast development. At the time of the patient's birth the mother was 37 years old and the father 42 years old. There is no parental consanguinity.

The baby's physical and mental development was thought to be normal. Weights and lengths as recorded by the Health Centre Sister were consistently about 90th percentile for age.

We found her to be a healthy-looking baby, large but well proportioned. Height $(75 \mathrm{~cm}$.) and weight $(11.5$ kg.) were just above the 90 th percentile. Some enlargement of breast tissue was visible and palpable, but the nipples were infantile and not pigmented. The skin was fair with no abnormal pigmentation, and there was a little fine downy pubic and axillary hair. The labia minora appeared a little hypertrophied and there was some blood-stained vaginal discharge. Her motor development and reactions to people were average for her age. No abnormality of the central nervous system was found. The head circumference was $47 \mathrm{~cm}$., the anterior fontanelle was nearly closed and the retinae were normal. On rectal examination the cervix was not felt.

The haemoglobin was $9.8 \mathrm{~g} . / 100 \mathrm{ml}$., and the blood smear was compatible with blood loss and iron deficiency. Radiographs of the chest, skull and long bones were normal, but the bone age was a little advanced (1 year 9 months). The 24-hour urinary outputs of the relevant hormone excretion products were as follows: neutral 17-ketosteroids, $0.8 \mathrm{mg}$. (Callow and Callow); 17 hydroxycorticosteroids, $4.9 \mathrm{mg}$. (modified Porter and Silber); pregnanediol, 0.65 mg. (Morris, 1959, as modified by Hill, 1960); pregnanetriol, nil (Bongiovanni and Clayton, 1954); oestrone less than $0.2 \mathrm{mg}$. (J. B. Brown, 1961, personal communication). A test for follicular-stimulating hormone on a 48-hour urine collection was negative (at 4 mouse units per day) (Johnsen, 1958).

At this point no definitive diagnosis could be made so the baby was examined under a general anaesthetic. A normal infantile cervix was seen and felt, but no biopsy of the endometrium was obtained as the cervical os could not easily be dilated. Rectally, the left ovary felt normal, but a very mobile mass about $6 \mathrm{~cm} . \times 3 \mathrm{~cm}$. was felt on the right side.

On a second occasion these findings were confirmed, 


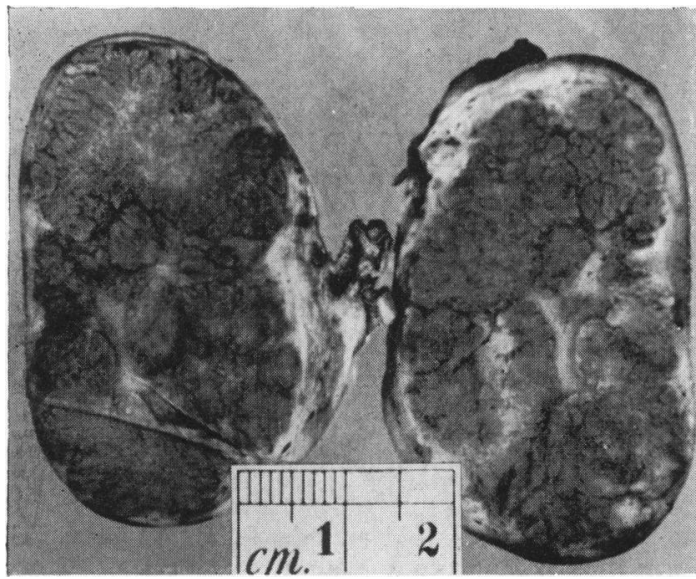

FIG. 1.-Longitudinal section through the tumour showing the cut surface.

and laparotomy showed the uterus to be moderately enlarged and the tubes normal. The left ovary was infantile (1-1.5 cm. long) but contained two tiny $(2-3 \mathrm{~mm}$.) cysts. The right ovary was replaced by a smooth solid ovoid white mass which was removed after dissecting off the normal fibrinated end of the right uterine tube.

Apart from a slight wound infection and some bronchitis the child recovered quickly from this pro- cedure. The vaginal bleeding, which had ceased preoperatively, did not recur.

A vaginal smear taken two days after operation showed mainly intermediate cells with a few clumps of more cornified cells resembling those seen in the adult in the luteal phase of the menstrual cycle.

Follow Up. When seen three months after operation, there had been no further vaginal bleeding, there was no palpable breast tissue and the labia minora appeared normal. Her growth pattern had not altered and remained in the vicinity of the 90 th percentile-in this she resembled three of her siblings.

Pathological Report. The tumour was roughly eggshaped and was slightly lobulated, measuring $4.5 \times 3 \times$ $2.5 \mathrm{~cm}$. The outer surface was smooth and whitish and on one side the capsule was somewhat translucent revealing yellow nodules of tissue beneath the surface. When the tumour was cut (Fig. 1), the bulk of it was composed of masses of canary yellow tissue with a rim of white tissue at the periphery varying from $1 \mathrm{~mm}$. to $4 \mathrm{~mm}$. in thickness. The yellow masses had a scalloped outer margin where they were sharply demarcated from the white cortical tissue, and were divided up, rather like irregular segments of an orange, by radiating bands of fibrous tissue. The entire tumour was seen to consist of these uniformly bright yellow masses.

Histologically the outer rim consisted of flattened, but otherwise normal ovary. One or two small follicular

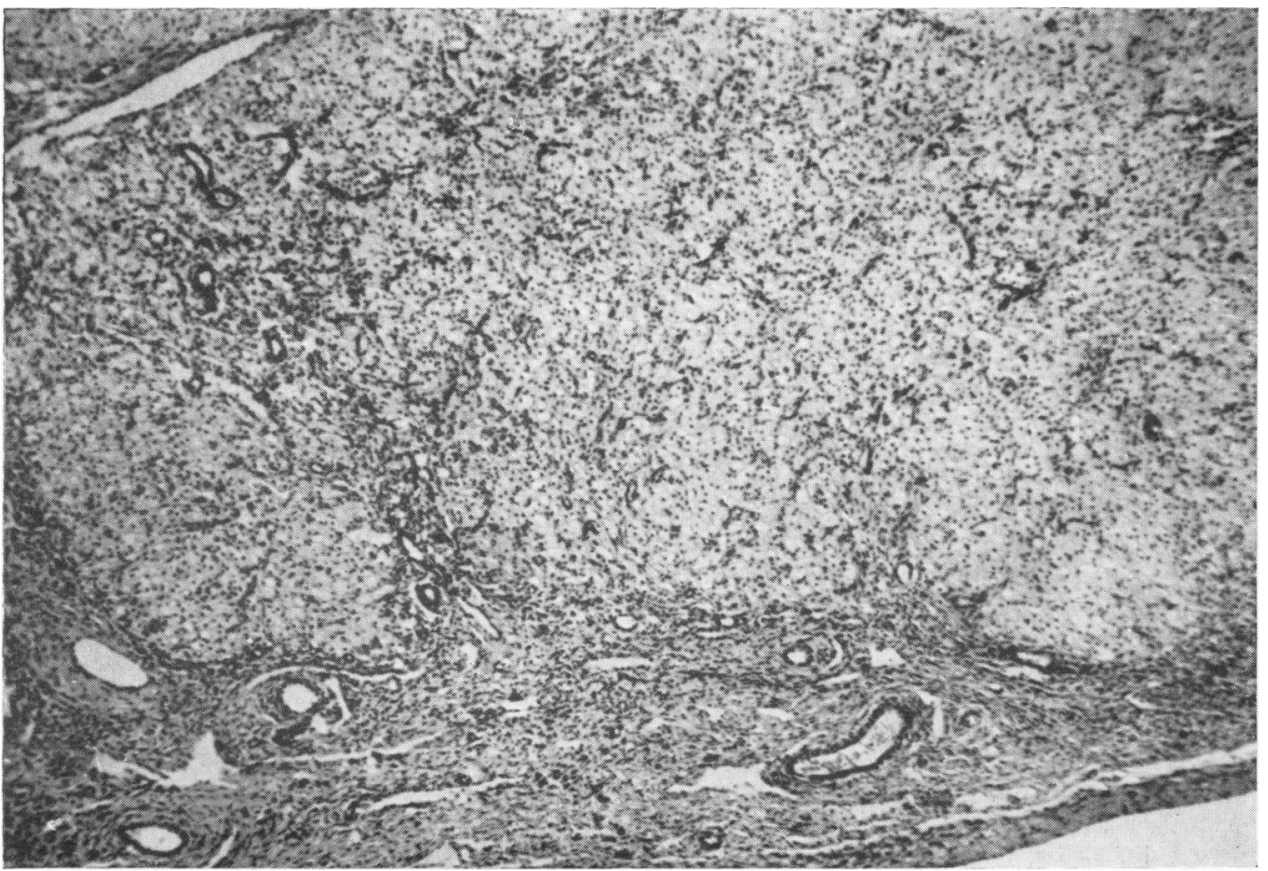

Fig. 2.-Representative portion of the tumour showing the clear demarcation between the flattened ovarian parenchyma and the masses of luteal cells. (H. and E. $\times 36$.) 
cysts and a few developing follicles were visible. The macroscopically yellow areas consisted of festoons of large clear cells with small nuclei, which in their appearance and arrangement bore a striking resemblance to the adult corpus luteum (Figs. 2, 3, 4). Fat stains demonstrated numerous lipid droplets in the cytoplasm of these cells (Fig. 5).

The septa dividing the luteal cell masses from one another varied in cellularity, in some parts resembling closely the stroma of a mature ovary, on other areas consisting of wider bands composed of plump spindleshaped cells (Fig. 3). In these areas the luteal cells were not clearly demarcated but tended to merge with the outermost of these spindle-shaped cells. The arrangement of the latter was reminiscent of a thecoma pattern but no part of the tumour that was examined resembled a granulosa cell tumour.

\section{Discussion}

Reviewers (Jolly, 1955; Seckel and Plotz, 1955; Wilkins, 1957; Eberlein et al., 1960) of the literature pertinent to sexual precocity and pseudoprecocity in infancy and childhood have been able to find only one report of a solid luteoma-like tumour as the cause (Seckel and Plotz, 1955). Even in this case the tumour was of a granulosa cell type with large areas of luteinization; however, the evidence for progesterone secretion and of luteinizing effects was good.

Other cases have been reported in which ovarian cysts with areas of luteinization were found, but in some reports it is hard to be sure whether these are the primary cause, or secondary to a pituitary lesion. Some such cysts do, however, seem to have been the primary cause of the precocious development.

In this case the tumour is histologically homogeneously lutein in type. Chemical studies did not show convincing evidence of progesterone secretion, but the vaginal mucosa showed luteinization. Unfortunately no endometrial tissue was obtained.

True luteomas of the ovary, even in adults, are very uncommon tumours. Luteinization of theca cells and also of granulosa cells is not infrequently seen in granulosa and granulosa-theca tumours of children and adults. Willis (1960) states that 'the granulosa-theca-luteal group of tumours form a single histogenetic class, representing the follicleformative ovarian parenchyma, showing great structural diversity just as might be expected of tumours of such an origin, and often secreting oestrogens in excess'. He agrees with Henderson (1942) that luteal structure is common in granulosa cell tumours and 'is sometimes predominant, giving

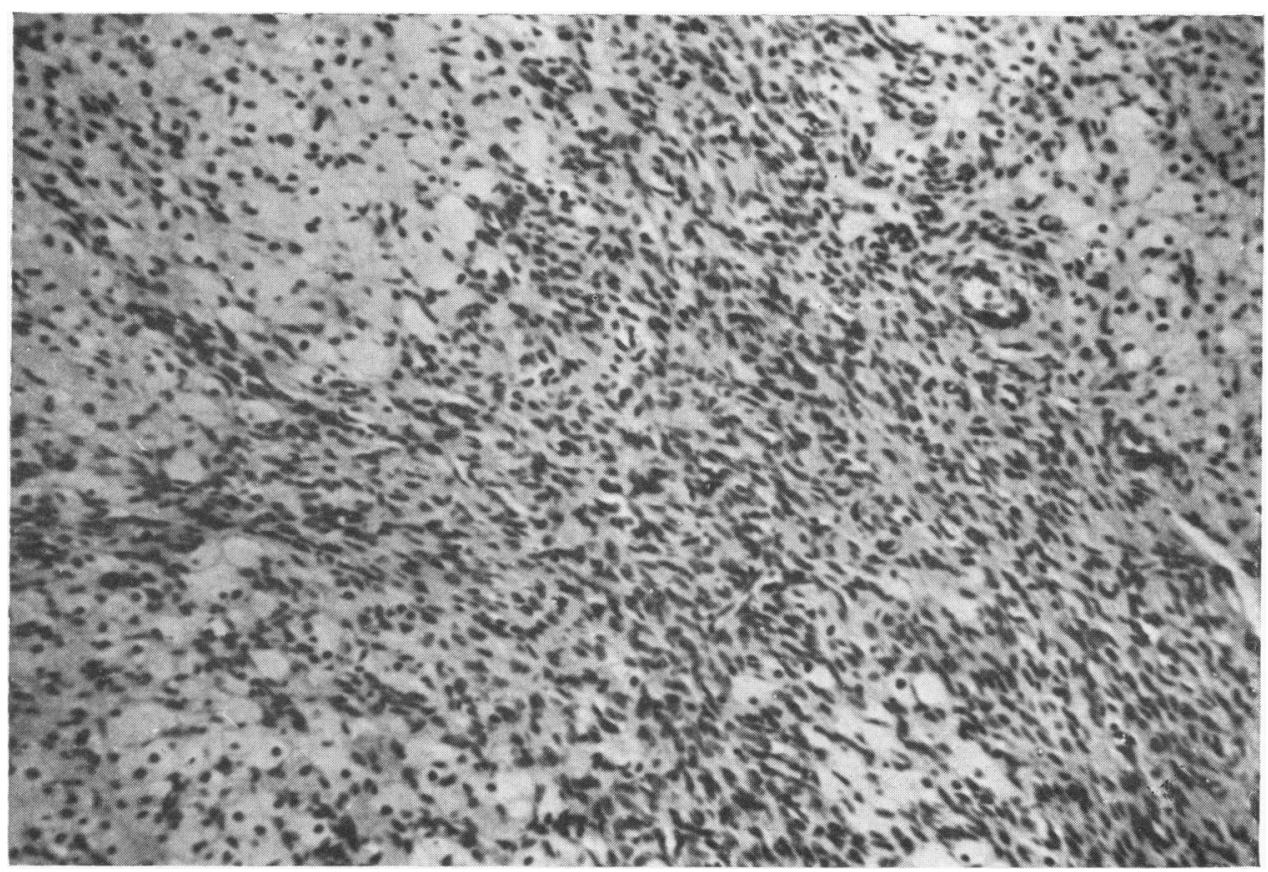

FIG. 3.-Edge of a mass of luteal cells showing the spindle-shaped stromal cells. (H. and E. $\times 108$.) 


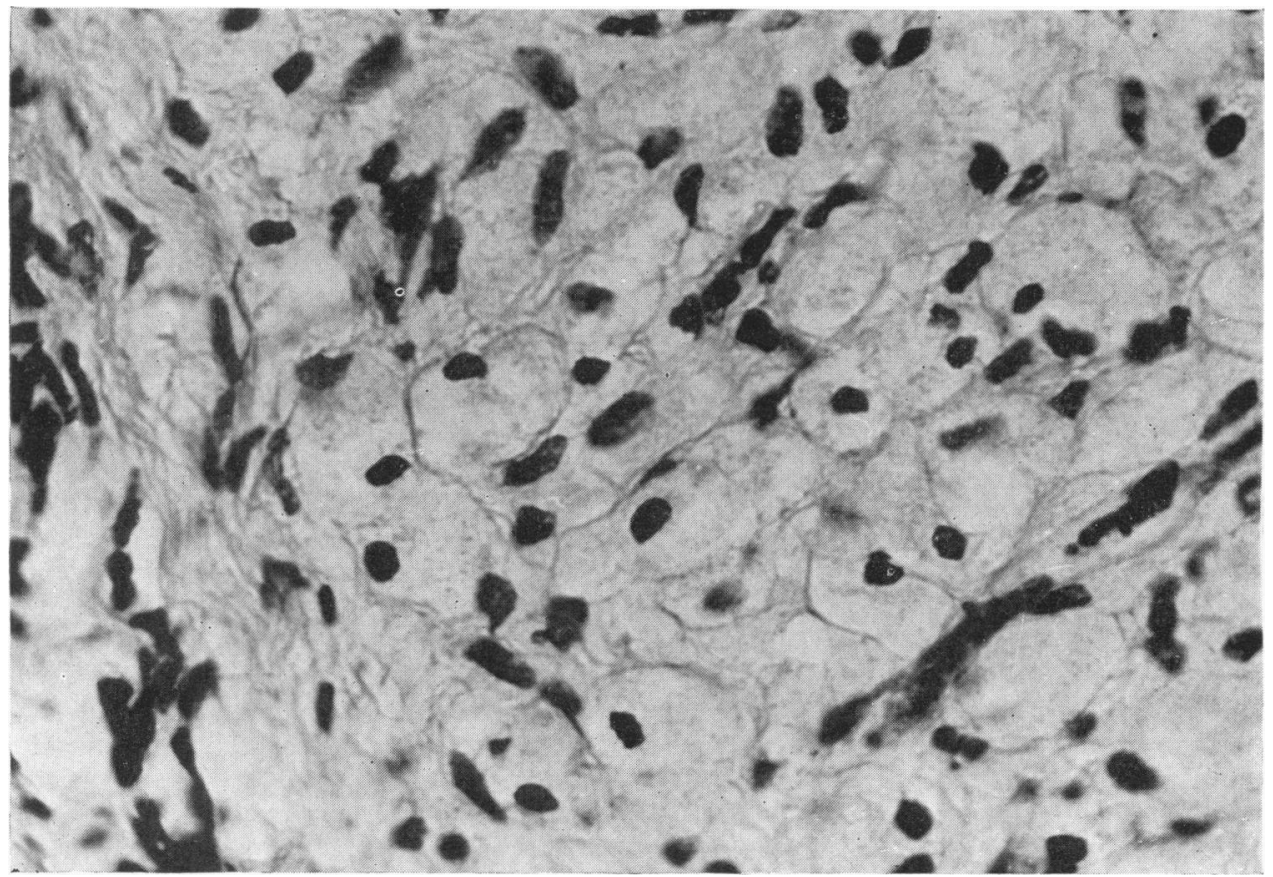

Fig. 4. - The fine detail of the cells composing the bulk of the tumour. (H. and E. $\times 442$.)

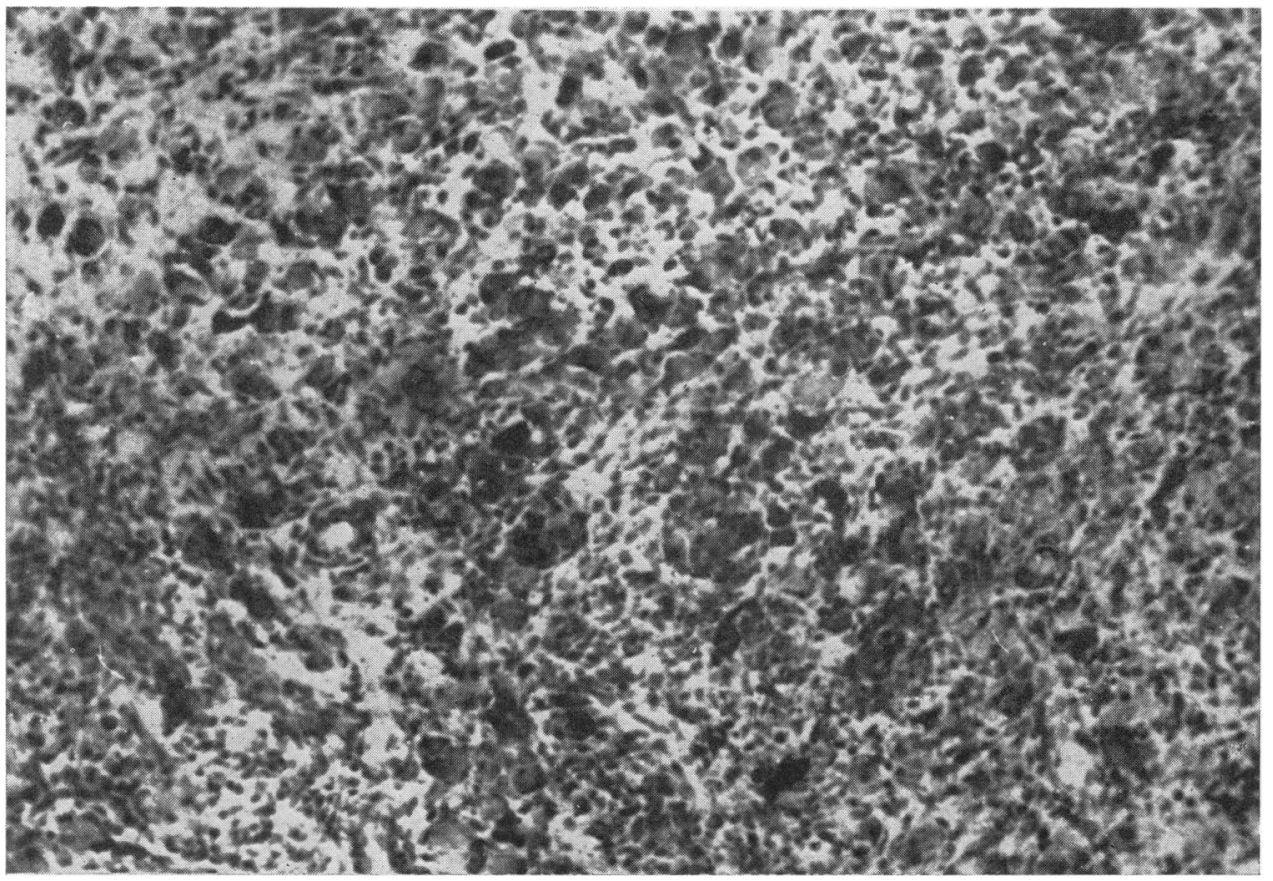

FIG. 5.-A fat stain demonstrates the large droplets of neutral fat in the tumour cells. (Oil-red-O $\times 108$. 
the tumour a bright yellow colour like a giant corpus luteum'. When one finds in a child of 10 months an entire tumour composed of luteal-like cells, arranged in festoons and with the scalloped edge characteristic of the adult corpus luteum and with no evidence, in multiple sections, of a pattern resembling granulosa cells, then the term luteoma seems justified. Whether the tumour arose de novo as a mass of luteal-like cells or whether it originated in the process of luteinization of granulosa-theca cells is probably unanswerable. Certainly its behaviour was that of a progesterone-secreting tumour and as such it is of considerable pathological interest.

Since an ovarian tumour is a curable cause of precocious sexual development it is important not to miss any cases. In 1957 Wilkins pointed out that the luteoma reported by Seckel and Plotz (1955) was the only ovarian tumour which had not been palpable at the time of presentation. These authors do not report any findings by palpation under anaesthesia, and the tumour was of the same size as that in our case. Probably it is still safe to suggest that inability to feel a pelvic mass under anaesthesia excludes an ovarian tumour as the cause of the precocious development, and in such a case laparotomy is not necessary.

\section{Summary}

A case of pseudoprecocity in an 10-month-old girl is reported. Hormone assays in the urine showed only a mild rise in pregnanediol excretion; the vaginal smear showed a pattern similar to that seen in an adult in the luteal phase of the menstrual cycle. Removal of a solid right ovarian tumour resulted in cure, and histological examination showed it to be a luteoma of the ovary.

Urinary oestrone estimations were made by Dr. R. I. Cox and Dr. F. I. R. Martin tested the urine for follicularstimulating hormone. We thank Dr. H. E. Williams for encouraging us to study and report this case, which was under his care, and Dr. A. L. Williams for his advice.

\section{REFERENCES}

Bongiovanni, A. M. and Clayton, G. W., Jr. (1954). A simplified method for the routine determination of pregnanediol and pregnanetriol in urine. Bull. Johns Hopk. Hosp., 94, 180.

Eberlein, W R , Bongiovanni, A M Jones, I T and Yakovac W. C. (1960). Ovarian tumors and cysts associated with sexual precocity J Pediat 57, 484

Henderson. N. (1942), 57, 484 . ovary. Amer. J. Obstet. Gynec., 43, 194.

Hill, E. E. (1960). Chromatography of the 17-ketogenic steroids in the diagnosis and control of congenital adrenal hyperplasia. Acta endocr. $(K b h), 33,230$.

Johnsen, S. G. (1958). A clinical rout ine-method for the quantitative determination of gonadotrophins in 24-hour urine samples. ibid., 28, 69.

Jolly, H. (1955). Sexual Precocity (American Lecture Series No. 200). Charles C. Thomas, Springfield, Illinois.

Morris, R. (1959). Pregnanetriol in urine: Determination as a 17-ketogenic steroid. Acta endocr. $(K b h), 32,596$.

Schultz, O. T. (1926). Tumors of infancy and childhood. In Pediatrics, ed. I. A. Abt, Vol. 8, pp. 641-865. Saunders, Philadelphia.

Seckel, H. P. G. and Plotz, E. J. (1955). Sexual precocity due to estrogen- and progesterone-producing organoid luteoma of the ovary. Z. Kinderheilk., 76, 593 .

Wilkins, L (1957) The Diagnosis and Treatment of Endocrine Disorders in Childhood and Adolescence, 2nd ed. Blackwell, Disorders

Willis, R. A. (1960). Pathology of Tumours, 3rd ed. Butterworth, London. 